Article

\title{
Complete Stress-Strain Curves of Self-Compacting Steel Fiber Reinforced Expanded-Shale Lightweight Concrete under Uniaxial Compression
}

\author{
Mingshuang Zhao ${ }^{1,2, *(D)}$, Bingxin Zhang ${ }^{3}$, Pengran Shang ${ }^{3}$, Yan Fu ${ }^{3}$, Xiaoyan Zhang ${ }^{1,3}$ and \\ Shunbo Zhao ${ }^{1,2, *(\mathbb{D})}$ \\ 1 International Joint Research Lab for Eco-building Materials and Engineering of Henan, North China \\ University of Water Resources and Electric Power, Zhengzhou 450045, China; zxyanzi@ncwu.edu.cn \\ 2 Henan Provincial Collaborative Innovation Center for Water Resources High-efficient Utilization and \\ Support Engineering, Zhengzhou 450046, China \\ 3 School of Civil Engineering and Communications, North China University of Water Resources and Electric \\ Power, Zhengzhou 450045, China; Z201710313234@stu.ncwu.edu.cn (B.Z.); prshang@stu.ncwu.edu.cn (P.S.); \\ yanfu@stu.ncwu.edu.cn (Y.F.) \\ * Correspondence: zhaoms@stu.ncwu.edu.cn (M.Z.); sbzhao@ncwu.edu.cn (S.Z.); \\ Tel.: +86-0371-6912-7378 (S.Z.)
}

Received: 22 August 2019; Accepted: 13 September 2019; Published: 14 September 2019

\begin{abstract}
To expand the structural application of steel fiber reinforced expanded-shale lightweight concrete (SFRELC), a self-compacting SFRELC with high-workability was developed based on previous research. As part of the investigation, the present study focuses on the adaptability of formulas used for the complete stress-strain curves of steel fiber reinforced lightweight-aggregate concrete and conventional concrete under uniaxial compression. On the basis of mix proportion of SFRELC, self-compacting SFRELC was designed with the volume fraction of steel fiber as $0 \%$, $0.4 \%, 0.8 \%, 1.2 \%, 1.6 \%$, and $2.0 \%$. Eighteen cylindrical specimens with dimensions of $\Phi 150 \mathrm{~mm} \times$ $300 \mathrm{~mm}$ were tested to measure the uniaxial compressive stress-strain curves of self-compacting SFRELC. Results indicated that, with the increasing volume fraction of steel fiber, the compressive strain at the peak-stress of the stress-strain curve increased, while the slope of the descending portion decreased. This increased the energy absorption of self-compacting SFRELC with a higher compression toughness. With a comparison of test results between four groups of calculation models, a group of formulas is selected to express the complete stress-strain curves of self-compacting SFRELC under uniaxial compression.
\end{abstract}

Keywords: steel fiber reinforced expanded-shale lightweight concrete (SFRELC); self-compacting; volume fraction of steel fiber; uniaxial compressive stress-strain curve; compression toughness ratio; calculation model

\section{Introduction}

In view of the brittleness of lightweight-aggregate concrete [1-3], and the utilization of local sintered expanded-shale as fine and coarse aggregates, a new concrete material called steel fiber reinforced expanded-shale lightweight concrete (SFRELC) was developed. To investigate SFRELC with different flowabilities, classified as plastic, flowing, and high flowing with the slump varied from $60 \mathrm{~mm}$ to $200 \mathrm{~mm}$, a series of experimental investigations have been performed to study the mechanical properties, including compressive strength and toughness, tensile strength, flexural strength and toughness, deformation and modulus of elasticity, strength developments and complete stress-strain curves [4-12], carbonization and freeze-thaw resistance [10,13], as well as autogenous and drying 
shrinkage [14]. This confirmed the good mechanical performance, durability, and steady volume of SFRELC. To further enlarge the application of SFRELC, self-compacting technology is worthy of study, in order to support the mechanical vibration procedure during construction [15-21]. As a core point, the stress-strain relationship of self-compacting SFRELC is of great importance for the design of concrete structures.

Based on previous studies, the stress-strain relationship of vibro-compacting lightweight aggregate concrete (LAC), with or without steel fiber, has been conducted by some researchers [11,22-31]. For LAC, with the peak stress varied from $18 \mathrm{MPa}$ to $89 \mathrm{MPa}$, peak strains also presented an increasing tendency from about $2000 \mu \varepsilon$ to $6000 \mu \varepsilon$, while the ratios of peak stress to strain, namely the secant modulus, significantly increased from $7 \mathrm{GPa}$ to $15 \mathrm{GPa}$. The secant modulus was lower than 12-25 GPa of normal weight concrete (NWC), and this is due to the shape of the stress-strain curves being more linear as the peak stress of LAC increased with the higher deformability [22-27]. While in Campione's study [25], the residual stress in the descending portion was about $26 \%$ of the peak stress for LAC and $67 \%$ for NWC at the same strain of $6000 \mu \varepsilon$. Compared with the shape of the compressive stress-strain curves for LAC, more brittle behavior, namely a steeper and shorter descending curve, was observed with respect to NWC of the same strength.

Steel fiber was added to enhance the toughness of LAC, while the stress-strain relationship of steel fiber reinforced lightweight-aggregate concrete (SFRLAC) was significantly influenced. According to researches $[11,25,29-31]$, hooked-ends steel fiber with aspect ratios of 60-67, or thin-plate cutting corrugated steel fiber with an aspect ratio of 27 , was used to enhance the LAC with expanded-shale or other kinds of lightweight aggregates. The results showed that the shape of ascending curves was almost similar with the increased peak stresses at about 0-29\%, the increased peak strains at about $15-55 \%$, while the secant modulus presented a decrement of about $5-33 \%$. Thus, the slope of the ascending portion of stress-strain in curves increased with the volume fraction of steel fiber, which indicates that the addition of steel fiber could promote the stiffness of SFRLAC. For the descending portion, slopes became smaller with the increasing volume fraction of steel fiber. The residual stresses of stress-strain curves for SFRLAC at a certain strain of $6000 \mu \varepsilon$ were about $47-76 \%$ of their peak stresses with the volume fraction of steel fiber of $2.0 \%[11,25,29,30]$. The effect of steel fiber on the promotion of the toughness and ductility of SFRLAC connected with the type and aspect ratio of steel fibers.

According to the experimental study of compressive stress-strain curves of vibro-compacting SFRELC, and the analysis a large number of test curves of LAC and SFRLAC, a unified stress-strain model was proposed for the prediction of complete compressive stress-strain curves of LAC and SFRLAC [11]. The proposed model was also modified and adopted by Ding et al. to get a good prediction for the complete compressive stress-strain curves of self-compacting steel fiber reinforced concrete (SFRC) under uniaxial compression [32]. Meanwhile, Aslani's model [33,34] was proposed to predict the stress-strain relationship of self-compacting fiber reinforced concrete with different strengths, at different curing ages, in their own experiments. Cunha's model $[35,36]$ was put forward based on the calculation model in CEB-FIP model code 1990 [37] for self-compacting fiber reinforced concrete. The results showed that Cunha's model had a good prediction for the ascending portion but underestimated for the descending portion of the compressive stress-strain curves in both Aslani's and Ding's researches.

Based on the above reviews, no study was carried out on the compressive stress-strain model of self-compacting SFRELC, and the adaptability and applicability of the present models of LAC and SFRLAC have not been confirmed. Therefore, this paper focuses on the assessment and numerical prediction of the complete stress-strain curves of self-compacting SFRELC under uniaxial compression. Eighteen cylindrical specimens were prepared for self-compacting SFRELC with a varying volume fraction of steel fiber from $0 \%$ to $2.0 \%$. Based on the test results, the proposed model, Aslani's model, Cunha's model, and the FIP model were verified to predict the stress-strain curve of self-compacting 
SFRELC. Meanwhile, the energy absorption ability of self-compacting SFRELC, as characterized by the compression toughness ratio, is also discussed.

\section{Preparation of Experimental Study}

\subsection{Raw Materials}

Common Portland cement meeting the requirements of China code GB 175 was used [38], of which the physical and mechanical properties are presented in Table 1. Fly ash satisfying the indices of class-II specified in China code GB/T1596 [39] was used as the admixture, the density was $2070 \mathrm{~kg} / \mathrm{m}^{3}$, the residual amount on a square hole sieve of $45 \mu \mathrm{m}$ was $20 \%$, and the water demand ratio was about $92 \%$. As in the previous study $[9,11]$ and presented in Figure $1 \mathrm{a}, \mathrm{b}$, high-strength sintering expanded shales in continuous gradation of 5-20 mm was used for the coarse aggregate, and the ceramsite sand, the byproduct of sintering expanded shale sieved as continuous gradation within $0.16-5 \mathrm{~mm}$ was used for the fine aggregate. The grading curves of coarse expanded-shales and ceramsite sand are drawn in Figure 2, their particle gradation basically met the requirement in China code GB/T 17431.2 [40]. The physical and mechanical properties are listed in Table 2, and the water absorption curves are displayed in Figure 3 to be used as the basis of selecting the presoaking time. At the same time, the $24 \mathrm{~h}$ water absorptions of expanded shale and ceramsite sand were measured as $7.45 \%$ and $9.75 \%$. Due to the water absorptions within $1 \mathrm{~h}$ reaching $93.5 \%$ and $92.6 \%$ of $24 \mathrm{~h}$ water absorptions for expanded shale and ceramsite sand respectively, the rational presoaking time was chosen as $1 \mathrm{~h}$. The steel fiber exhibited in Figure $1 \mathrm{c}$ was crimped cut with thin-plate, the length $l_{\mathrm{f}}=36.7 \mathrm{~mm}$, the equivalent diameter $d_{\mathrm{f}}=1.35 \mathrm{~mm}$, and the aspect ratio $l_{\mathrm{f}} / d_{\mathrm{f}}=27.2$. Others included the polycarboxylic acid superplasticizer with a water-reducing rate no less than $30 \%$, and tap water as mixing water.

Table 1. Physical and mechanical properties of cement.

\begin{tabular}{cccccccc}
\hline \multirow{2}{*}{$\begin{array}{c}\text { Density } \\
\left(\mathbf{k g} / \mathbf{m}^{\mathbf{3}}\right)\end{array}$} & $\begin{array}{c}\text { Water Requirement of } \\
\text { Normal Consistency } \\
\mathbf{( \% )}\end{array}$ & \multicolumn{2}{c}{$\begin{array}{c}\text { Setting Time } \\
(\mathbf{m i n})\end{array}$} & $\begin{array}{c}\text { Compressive Strength } \\
\mathbf{( M P a})\end{array}$ & \multicolumn{2}{c}{$\begin{array}{c}\text { Flexural } \\
\text { Strength } \mathbf{( M P a )}\end{array}$} \\
\cline { 3 - 8 } & 26.4 & Initial & Final & 3d & 28d & 3d & 28d \\
\hline 3085 & 160 & 245 & 29.4 & 54.7 & 6.2 & 9.4 \\
\hline
\end{tabular}

Table 2. Physical and mechanical properties of expanded shale and ceramsite sand.

\begin{tabular}{|c|c|c|c|c|c|}
\hline $\begin{array}{l}\text { Particle Size } \\
\quad(\mathrm{mm})\end{array}$ & $\begin{array}{l}\text { Apparent Density } \\
\left(\mathrm{kg} / \mathrm{m}^{3}\right)\end{array}$ & $\begin{array}{l}\text { Bulk Density } \\
\left(\mathrm{kg} \cdot \mathrm{m}^{3}\right)\end{array}$ & $\begin{array}{c}1 \mathrm{~h} \text { Water } \\
\text { Absorption (\%) }\end{array}$ & $\begin{array}{c}\text { Mud } \\
\text { Content (\%) }\end{array}$ & $\begin{array}{c}\text { Cylinder Compressive } \\
\text { Strength (MPa) }\end{array}$ \\
\hline $5-20$ & 1262 & 827 & 6.98 & 0.7 & 7.4 \\
\hline $0.16-5$ & 1350 & 850 & 9.02 & 0.11 & - \\
\hline
\end{tabular}

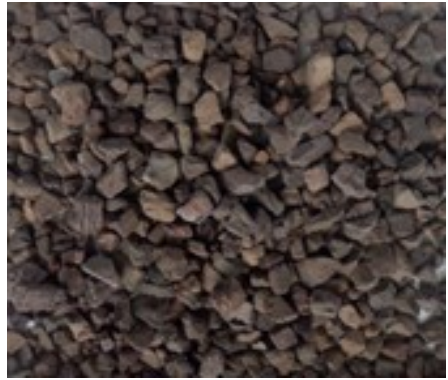

(a)

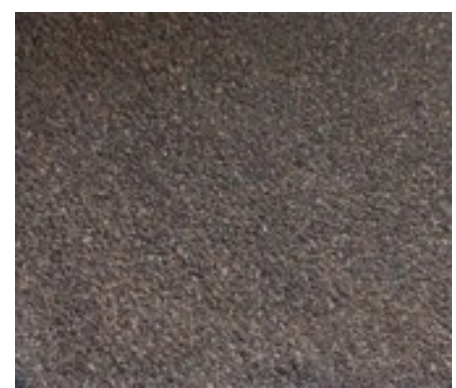

(b)

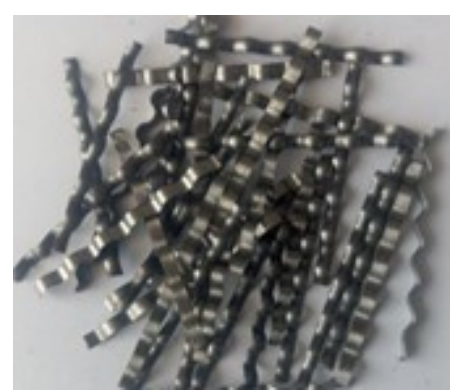

(c)

Figure 1. Figures of raw materials: (a) coarse expanded-shale; (b) ceramsite sand; (c) steel fiber. 


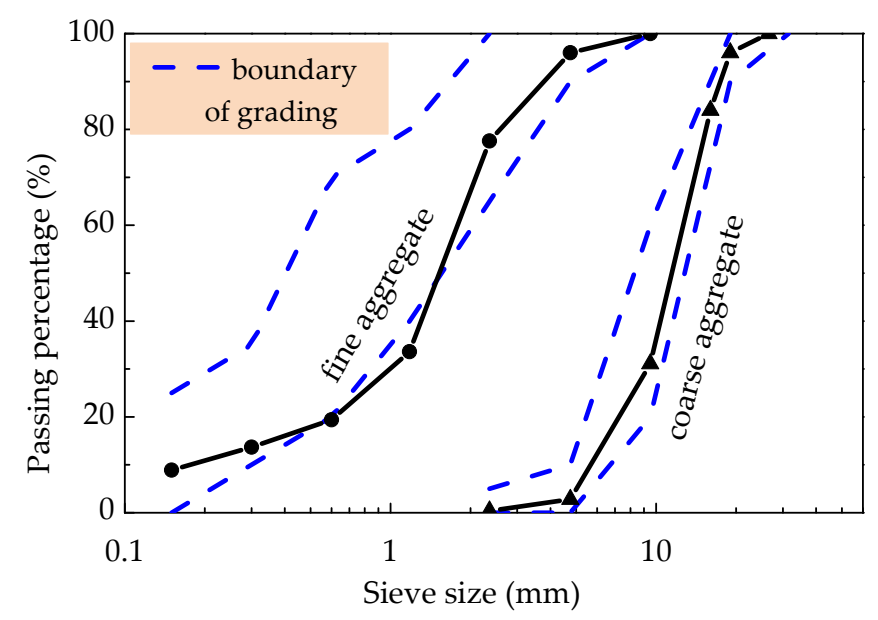

Figure 2. Grading curves of coarse expanded-shale and ceramsite sand.

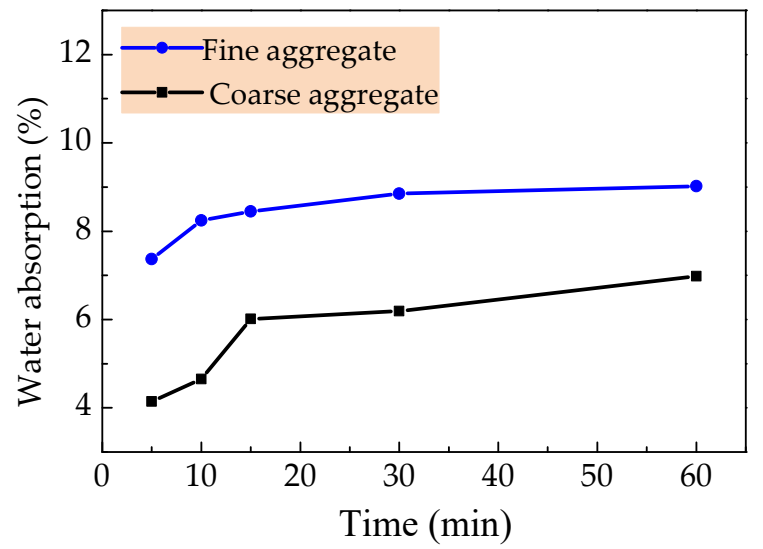

Figure 3. Water absorption curves of ceramsite sand and coarse expanded-shale.

\subsection{Mix Proportions}

The water/binder ratio $(w / b)$ was chosen as 0.30 to make the self-compacting SFRELC. The volume fraction of steel fiber $v_{\mathrm{f}}=0 \%, 0.4 \%, 0.8 \%, 1.2 \%, 1.6 \%$, and $2.0 \%$, respectively. The volume ratio of ceramsite sand was $50 \%$ when $v_{\mathrm{f}}=0 \%, 0.4 \%$, and $0.8 \%$, and then increased $0.2 \%$ with the increment of $v_{\mathrm{f}}=0.4 \%$. About $30 \%$ mass of cement was replaced by fly-ash. The details of mix proportion are presented in Table 3. Where the dosage of super-plasticizer was determined through testing according to the workability of fresh self-compacting SFRELC. As the saturated dry surface condition of expanded shale and ceramsite sand was adopted for the preparation of a fresh mixture of SFRELC, the dosage of presoaking water with $1 \mathrm{~h}$ water absorption was added additionally.

Table 3. Mix proportion of self-compacting SFRELC.

\begin{tabular}{|c|c|c|c|c|c|c|c|}
\hline$w / b$ & $\begin{array}{c}v_{f} \\
(\%)\end{array}$ & $\begin{array}{l}\text { Volume Ratio } \\
\text { of Sand } \\
(\%)\end{array}$ & $\begin{array}{l}\text { Cement } \\
\left(\mathrm{kg} / \mathrm{m}^{3}\right)\end{array}$ & $\begin{array}{l}\text { Fly Ash } \\
\left(\mathrm{kg} / \mathrm{m}^{3}\right)\end{array}$ & $\begin{array}{c}\text { Coarse } \\
\text { Aggregate } \\
\left(\mathrm{kg} / \mathrm{m}^{3}\right)\end{array}$ & $\begin{array}{c}\text { Fine } \\
\text { Aggregate } \\
\left(\mathrm{kg} / \mathrm{m}^{3}\right)\end{array}$ & $\begin{array}{l}\text { Super-Plasticizer } \\
\left(\mathrm{kg} / \mathrm{m}^{3}\right)\end{array}$ \\
\hline \multirow{6}{*}{0.30} & 0 & 50 & \multirow{6}{*}{408} & \multirow{6}{*}{175} & 424 & 417 & 0.210 \\
\hline & 0.4 & 50 & & & 419 & 422 & 0.210 \\
\hline & 0.8 & 50 & & & 413 & 428 & 0.210 \\
\hline & 1.2 & 52 & & & 391 & 450 & 0.214 \\
\hline & 1.6 & 54 & & & 368 & 472 & 0.222 \\
\hline & 2.0 & 56 & & & 346 & 494 & 0.231 \\
\hline
\end{tabular}




\subsection{Test Methods}

The expanded shale and ceramsite sand were presoaked for $1 \mathrm{~h}$, and then mixed with cement, fly ash and steel fiber using a horizontal spindle forced mixer. The workability of fresh self-compacting SFRELC was measured according to the specifications in China code JGJ/T283 [41]. Three cubic specimens with dimension of $150 \mathrm{~mm}$ were used to test the compressive strength, three cylinder specimens with dimensions of $\Phi 150 \mathrm{~mm} \times 300 \mathrm{~mm}$ were used for measuring the uniaxial compressive stress-strain curves, and the mean values were adopted in accordance with the test method in China standards GB/T50081 [42], CECS13:2009 [43], and ACI 544.4R [44]. Specimens were cured in a standard curing room at $(20 \pm 2){ }^{\circ} \mathrm{C}$ temperature and $95 \% \mathrm{RH}$ for 28 days before testing.

With the requirement of the sufficient rigidity of test machine to get a complete stress-strain curve of concrete under uniaxial compression [11], a $3000 \mathrm{kN}$ electro-hydraulic servo universal testing machine with sufficient rigidity and higher loading control precision made by SANS Co. Ltd., as exhibited in Figure 4, was used as a loading device in this study. The loading speed was maintained as the strain rate among $(20-50) \times 10^{-6} / \mathrm{s}$. The stress and strain data were measured by a load transducer and two displacement meters on two symmetric sides of each specimen.

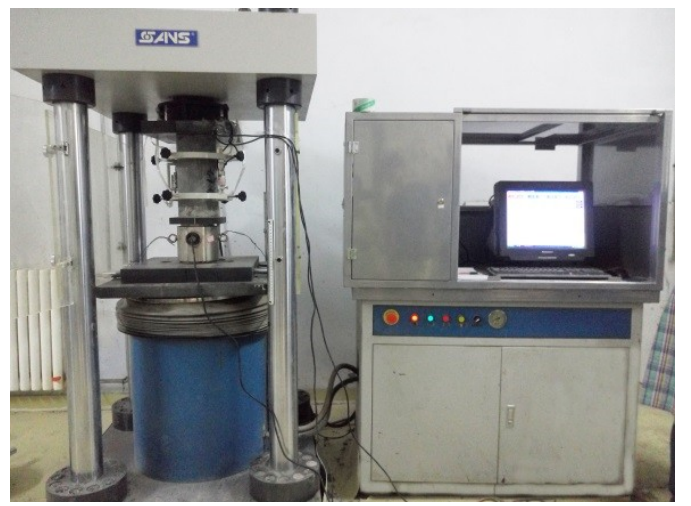

(a)

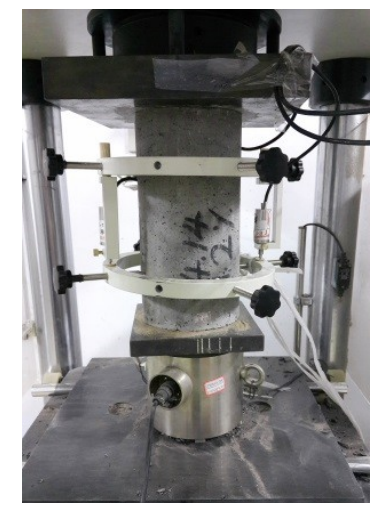

(b)

Figure 4. Equipment and instrument used in the test: (a) overall perspective; (b) testing device for load and deformation.

\section{Results and Analysis}

\subsection{Workability and Density}

Figure 5 displays the inverted slump cone method for slump flow and J-ring slump flow tests to evaluate the filling and passing abilities of self-compacting SFRELC. Test results are illustrated in Figures 6 and 7. Represented by the decreased slump-flow, J-ring slump flow, and the increased slump-flow time $\left(T_{500}\right)$, the filling ability decreases with the increase of $v_{\mathrm{f}}$. With the $v_{\mathrm{f}}$ increasing from $0 \%$ to $2.0 \%$, the slump flow and J-ring slump flow deceased $13.5 \%$ and $27.9 \%$, respectively, while the $T_{500}$ increased from $2.35 \mathrm{~s}$ to $7.04 \mathrm{~s}$. The maximum value of $T_{500}$ took place corresponding to the minimum slump flow at $v_{\mathrm{f}}=1.2 \%$. This is due to the insufficient dosage of water reducer. The J-ring slump-flow expressed a faster reduction than the slump-flow, which indicated a fast declination of passing ability of self-compacting SFRELC with the increase of $v_{\mathrm{f}}$. In general, the slump-flows for all mixes of self-compacting SFRELC were $610-780 \mathrm{~mm}$, which met the performance level $S F 1$ and SF2 specified in China code JGJ/T283 [41]. J-ring slump flows were $505-715 \mathrm{~mm}$, and the $T_{500}$ was longer than $2 \mathrm{~s}$. This met the requirements of a reinforced concrete structure cast by self-compacting SFRELC $[34,36]$. 


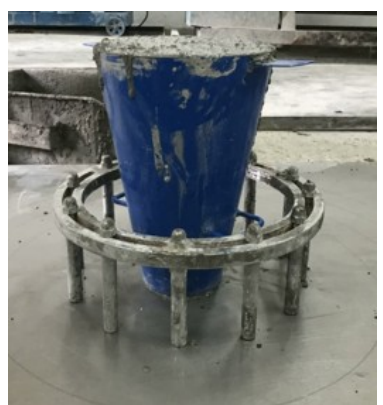

(a)

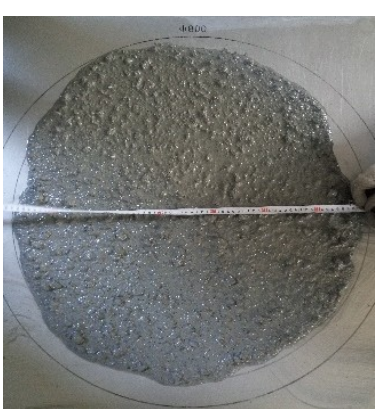

(b)

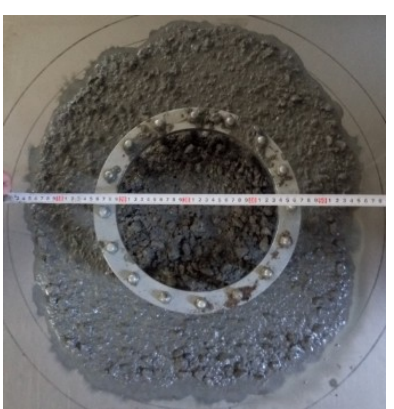

(c)

Figure 5. Tests for the workability of fresh self-compacting SFRELC: (a) testing device; (b) slump flow; (c) J-ring slump flow.

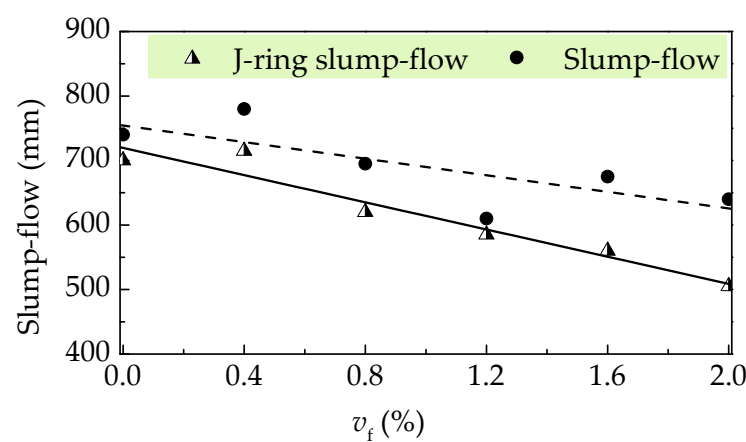

Figure 6. Slump flow with a varying $v_{\mathrm{f}}$.

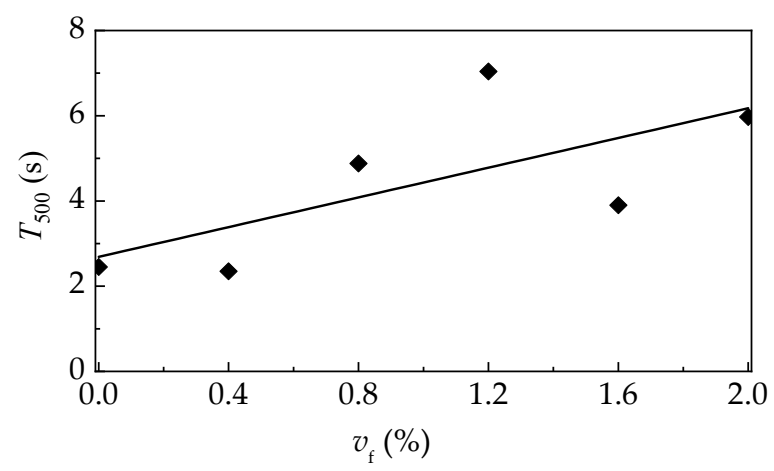

Figure 7. Slump flow time with a varying $v_{\mathrm{f}}$.

As presented in Figure 8, the air content of self-compacting SFRELC were more and more sensitive with the addition of steel fiber, especially when $v_{\mathrm{f}}$ was over $1.2 \%$. The air content grew slightly when $v_{\mathrm{f}}$ $=0-1.2 \%$ but had a great increase from $4.4 \%$ to $6.2 \%$ when $v_{\mathrm{f}}$ varied from $1.6 \%$ to $2.0 \%$. However, the densities of self-compacting SFRELC increased with $v_{\mathrm{f}}$ despite the increase of air content. This is due to the larger density of steel fiber. It should be noted that the higher air content may lead the reduce of the densities of self-compacting SFRELC, as displayed in Figure 9. The dry density of self-compacting SFRELC ranges from $1542 \mathrm{~kg} / \mathrm{m}^{3}$ to $1784 \mathrm{~kg} / \mathrm{m}^{3}$. It is about $25.7-35.8 \%$ lower than that of NWC. 


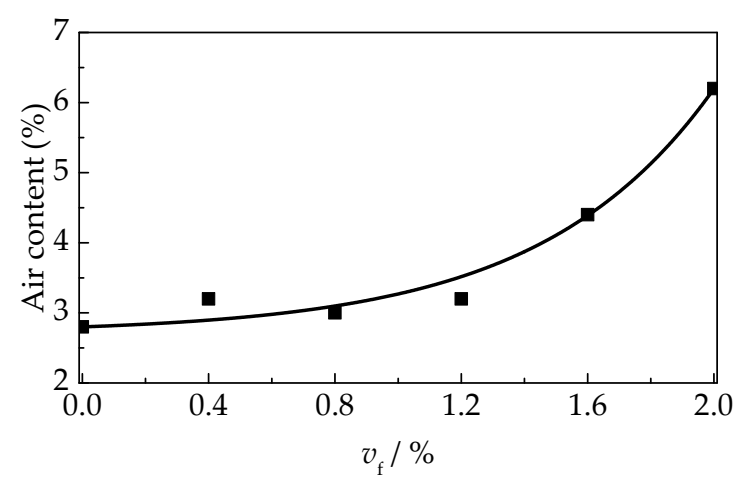

Figure 8. Variation of the air content with $v_{\mathrm{f}}$.

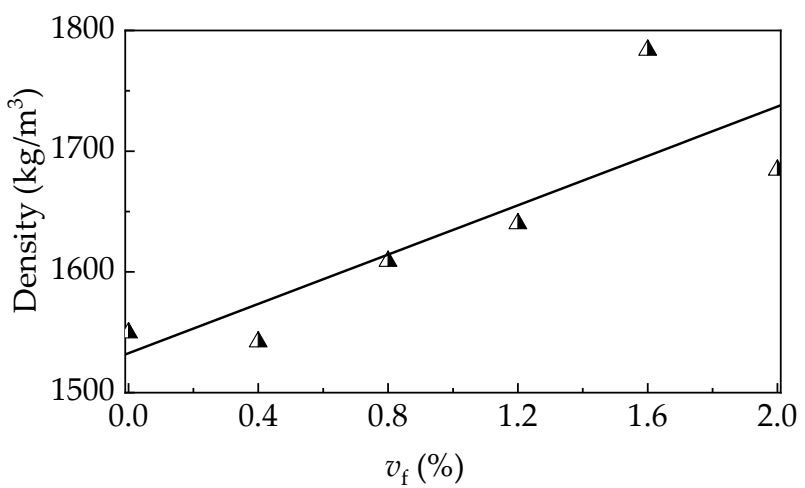

Figure 9. Variation of the density with $v_{\mathrm{f}}$.

\subsection{Uniaxial Compressive Stress-Strain Curves of Self-Compacting SFRELC}

Figure 10 presents the uniaxial compressive stress-strain curves of tested self-compacting SFRELC. With the increase of $v_{\mathrm{f}}$, the curves had a trend with a steeper slope at the ascending portion and slower slope at the descending portion. The peak-stress $f_{\mathrm{c}, \mathrm{r}}$ and corresponding strain $\varepsilon_{\mathrm{c}, \mathrm{r}}$ trend increased linearly.

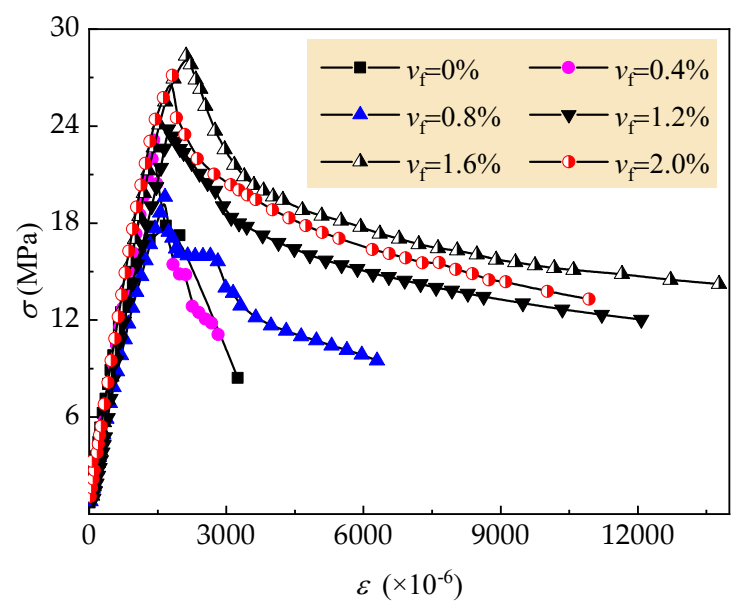

Figure 10. Stress-strain curves of tested self-compacting SFRELC with different $v_{\mathrm{f}}$.

The test results of peak-stress $\left(f_{c, r}\right)$ and peak strain $\left(\varepsilon_{c, r}\right)$ are summarized in Table 4 and exhibited in Figure 11, while the variation of cubic compressive strength $f_{\mathrm{cu}}$ is also displayed, in which the fiber factor $\lambda_{\mathrm{f}}=l_{\mathrm{f}} / d_{\mathrm{f}} \cdot v_{\mathrm{f}}=27.2 v_{\mathrm{f}}$. It can be seen that the compressive strengths and peak strains increased with the $v_{\mathrm{f}}$ due to the enhanced restraining effect of steel fiber on the transversal deformation of the specimen. With the $v_{\mathrm{f}}$ varying from $0 \%$ to $2.0 \%$, the increments of $f_{\mathrm{cu}}, f_{\mathrm{c}, \mathrm{r}}$ and $\varepsilon_{\mathrm{c}, \mathrm{r}}$ are $35.5 \%, 51.3 \%$ and 
27.1\%. According to the fitting formulas in Figure 11, the increment ratio of $f_{\mathrm{cu},} f_{\mathrm{c}, \mathrm{r}}$ and $\varepsilon_{\mathrm{c}, \mathrm{r}}$ with the increase of $v_{\mathrm{f}}$ are $0.562,1.090$ and 0.227 , respectively. This indicates that the effect of steel fiber on $f_{\mathrm{c}, \mathrm{r}}$ is higher than that on the $f_{\mathrm{cu}}$, and the values of $f_{\mathrm{c}, \mathrm{r}} / \varepsilon_{\mathrm{c}, \mathrm{r}}$ namely the secant modulus increase with the addition of steel fiber. The slope of ascending portion increased with the increasing volume fraction of steel fiber. Values of $f_{\mathrm{c}, \mathrm{r}}$ are about 0.6-0.8 times of $f_{\mathrm{cu}}$ in Table 4, which are lower than that reported in the experiments of Li et al. [7] of flowing SFRELC with the same raw materials and mix proportions. This may be attributed to the slower loading rate having a significant effect on the testing results.

Table 4. Test result of compressive strength and toughness.

\begin{tabular}{cccccccccc}
\hline $\boldsymbol{w} / \boldsymbol{c}$ & $\begin{array}{c}\boldsymbol{v}_{\mathbf{f}} \\
(\mathbf{\%})\end{array}$ & $\lambda_{\mathbf{f}}$ & $\begin{array}{c}f_{\mathbf{c u}} \\
(\mathbf{M P a})\end{array}$ & $\begin{array}{c}f_{\mathbf{c}, \mathbf{r}} \\
(\mathbf{M P a})\end{array}$ & $\begin{array}{c}\varepsilon_{\mathbf{c}, \mathbf{r}} \\
\left(\times \mathbf{1 0}^{-3}\right)\end{array}$ & $\begin{array}{c}\varepsilon_{\mathbf{c}, \mathbf{u}} \\
\left(\times \mathbf{1 0}^{-3}\right)\end{array}$ & $\begin{array}{c}E_{\mathbf{c}} \\
(\mathbf{G P a})\end{array}$ & $\begin{array}{c}W_{\mathbf{c}, \mathbf{1 . 0}} \\
(\mathbf{N} \cdot \mathbf{m m})\end{array}$ & $\boldsymbol{R}_{\mathbf{e}, \mathbf{1 . 0}}$ \\
\hline \multirow{4}{*}{0.30} & 0 & 0 & 29.01 & 17.84 & 1.6801 & 3.1765 & 21.57 & 196766.1 & 0.42 \\
& 0.4 & 0.1088 & 30.92 & 23.13 & 1.4116 & 2.7317 & 17.14 & 255427.2 & 0.42 \\
& 0.8 & 0.2176 & 32.28 & 19.62 & 1.6569 & 6.0114 & 15.35 & 283445.1 & 0.55 \\
& 1.2 & 0.3264 & 31.30 & 23.8 & 1.7252 & 12.3964 & 15.13 & 406151.2 & 0.64 \\
& 1.6 & 0.4352 & 34.41 & 28.35 & 2.1190 & 13.9847 & 17.42 & 478505.5 & 0.64 \\
& 2.0 & 0.544 & 41.12 & 27.13 & 1.8224 & 10.4132 & 19.72 & 452164.4 & 0.63 \\
\hline
\end{tabular}

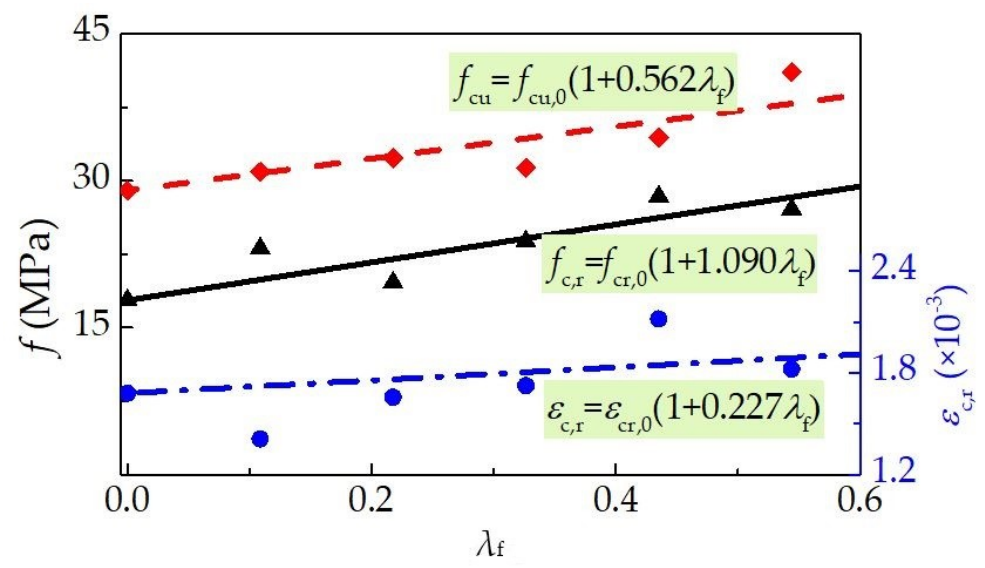

Figure 11. Variation of $f_{\mathrm{cu}}, f_{\mathrm{c}, \mathrm{r}}$ and $\varepsilon_{\mathrm{c}, \mathrm{r}}$ with a varying $\lambda_{\mathrm{f}}$.

According to China code GB50010 [45], $\varepsilon_{\mathrm{cu}}$ was defined as the strain corresponding to $0.5 f_{\mathrm{c}, \mathrm{r}}$ at the descending portion of stress-strain curves. The test results are presented in Table 4 , and exhibited in Figure 12 as the relative values of $\varepsilon_{\mathrm{cu}} / \varepsilon_{\mathrm{c}, \mathrm{r}}$ with a varying $\lambda_{\mathrm{f}}$. The obvious increasing relationship between $\varepsilon_{\mathrm{cu}} / \varepsilon_{\mathrm{c}, \mathrm{r}}$ and $\lambda_{\mathrm{f}}$ indicates that the ductility of self-compacting SFRELC after breaking was promoted by the addition of steel fibers. With the $v_{\mathrm{f}}$ increased from $0 \%$ to $2.0 \%, \varepsilon_{\mathrm{cu}} / \varepsilon_{\mathrm{c}, \mathrm{r}}$ was from 1.87 to $7.11,2.8$ times increase. The maximum value was achieved at $v_{\mathrm{f}}=1.2 \%$.

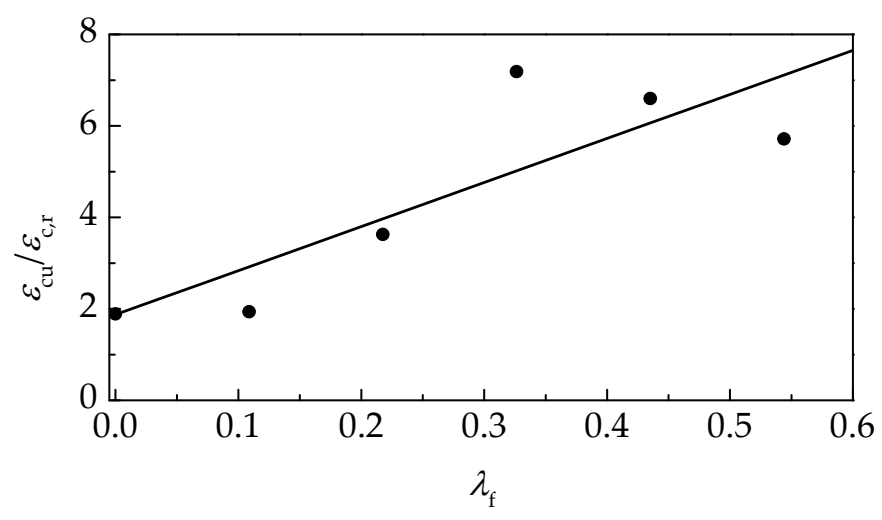

Figure 12. Change of $\varepsilon_{\mathrm{cu}} / \varepsilon_{\mathrm{c}, \mathrm{r}}$ with $\lambda_{\mathrm{f}}$. 


\subsection{Compression Toughness}

Table 4 summarizes the test results of compression absorbed energy $\left(W_{c, 1.0}\right)$ and compression toughness ratio $\left(R_{\mathrm{e}, 1.0}\right)$. The $W_{\mathrm{c}, 1.0}$ was calculated by the area under the compressive load-deformation curve within the uniaxial compressive deformation of $1.0 \%$ standard gauge length of $150 \mathrm{~mm}$, as presented in Figure 13. $R_{\mathrm{e}, 1.0}$ was used to evaluate the energy absorption ability of self-compacting SFRELC during compression deformation, which can be calculated as follows [9].

$$
R_{\mathrm{e}, 1.0}=\frac{W_{\mathrm{c}, 1.0}}{N_{\mathrm{p}} \cdot L_{0} \times 1.0 \%}
$$

where, $N_{\mathrm{p}}$ is the peak compressive load, $L_{0}$ is the standard gauge length.

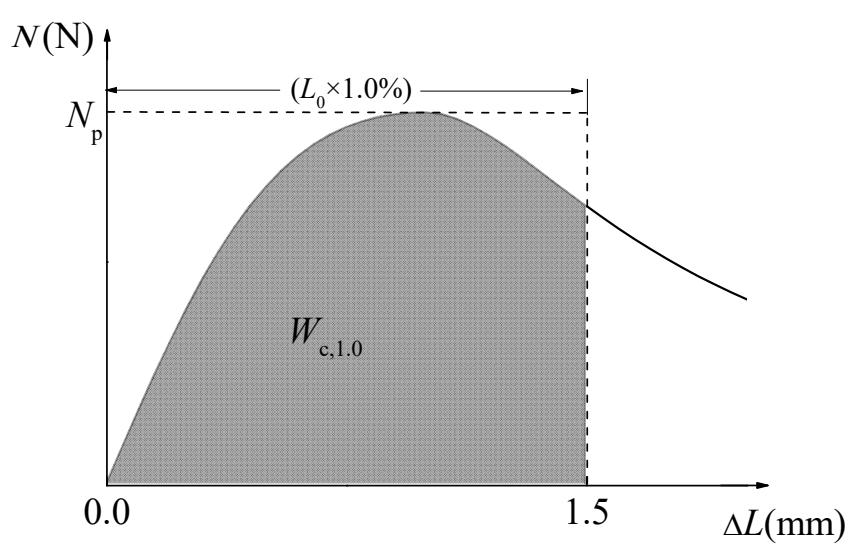

Figure 13. Calculation diagram for $R_{\mathrm{e}, 1.0}$.

Figure 14 presents the variations of compression absorbed energy $\left(W_{\mathrm{c}, 1.0}\right)$ and compression toughness ratio $\left(R_{\mathrm{e}, 1.0}\right)$. With the $v_{\mathrm{f}}=0.4 \%$, the presence of steel fiber improves $W_{\mathrm{c}, 1.0}$ about $30 \%$ but almost no enhancement on $R_{\mathrm{e}, 1.0}$. This indicates that the crack-bridging effect of smaller amount steel fibers mainly reflects at the pre-peak to arrest the transversal expanded deformation. With the $v_{\mathrm{f}}$ varying from $0.4 \%$ to $1.2 \%$, the toughening effect of steel fiber was outstanding, and the increments of $W_{\mathrm{c}, 1.0}$ and $R_{\mathrm{e}, 1.0}$ were $59 \%$ and $54.5 \%$, respectively. When the $v_{\mathrm{f}}$ increased to $1.6 \%$ or $2.0 \%, W_{\mathrm{c}, 1.0}$ and $R_{\mathrm{e}, 1.0}$ had no significant promotion. This may be due to the unfavorable effect of large content steel fibers on the compactness of self-compacting SFRELC, which results in the decrease of loading capacities after peak loads. According to previous test results [9], the $R_{\mathrm{e}, 1.0}$ of vibro-compacting SFRELC increased, even when $v_{\mathrm{f}}$ was up to $2.0 \%$. It can be said that the self-compacting SFRELC has a higher sensibility for steel fibers than the vibro-compacting SFRELC, and the volume fraction of steel fiber in self-compacting SFRELC should not be greater than $1.2 \%$.

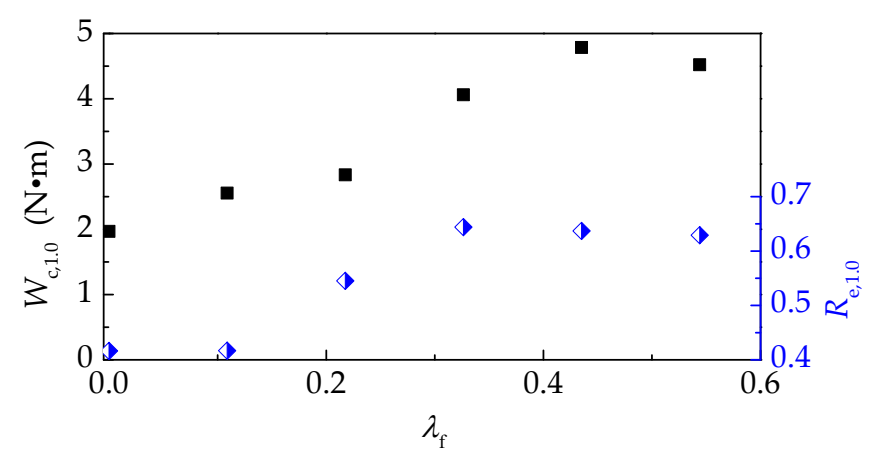

Figure 14. Variation of $W_{\mathrm{c}, 1.0}$ and $R_{\mathrm{e}, 1.0}$ with a varying $\lambda_{\mathrm{f}}$. 


\section{Evaluation for Compressive Stress-Strain Curve of Self-Compacting SFRELC}

\subsection{The Proposal Model}

According to the China code GB50010 and previous report [11,45], the complete stress-strain curve of lightweight aggregate concrete and vibro-compacting SFRELC can be expressed as Formulas (2)-(4). The ascending portion of the curves were calculated by Formula (2), and the coefficient $n$ was determined by Formula (3). The descending portions of curves were fitted using Formula (4), in which $\alpha_{\mathrm{c}}$ and $b$ are statistical parameters relating to the shape of descending portion of the stress-strain curve of lightweight aggregate concrete. According to the calculation model in report [11], $\alpha_{\mathrm{c}}$ is calculated by Formula (5). For vibro-compacting SFRELC, $\alpha_{\mathrm{cf}}$ and $b_{\mathrm{f}}$ have the same meanings with $\alpha_{\mathrm{c}}$ and $b$, and can be calculated by Formulas (6) and (7).

When $0 \leq \frac{\varepsilon_{\mathrm{c}}}{\varepsilon_{\mathrm{c}, \mathrm{r}}} \leq 1$,

$$
\begin{gathered}
\frac{\sigma_{\mathrm{c}}}{f_{\mathrm{c}, \mathrm{r}}}=\frac{n \frac{\varepsilon_{\mathrm{c}}}{\varepsilon_{\mathrm{c}, \mathrm{r}}}}{n-1+\left(\frac{\varepsilon_{\mathrm{c}}}{\varepsilon_{\mathrm{c}, \mathrm{r}}}\right)^{n}} \\
n=\frac{E_{\mathrm{c}} \varepsilon_{\mathrm{c}, \mathrm{r}}}{E_{\mathrm{c}} \varepsilon_{\mathrm{c}, \mathrm{r}}-f_{\mathrm{c}, \mathrm{r}}}
\end{gathered}
$$

When $\frac{\varepsilon_{\mathrm{c}}}{\varepsilon_{\mathrm{c}, \mathrm{r}}}>1$,

$$
\begin{gathered}
\frac{\sigma_{\mathrm{c}}}{f_{\mathrm{c}, \mathrm{r}}}=\frac{\frac{\varepsilon_{\mathrm{c}}}{\varepsilon_{\mathrm{c}, \mathrm{r}}}}{\alpha_{\mathrm{c}}\left(\frac{\varepsilon_{\mathrm{c}}}{\varepsilon_{\mathrm{c}, \mathrm{r}}}-1\right)^{b}+\frac{\varepsilon_{\mathrm{c}}}{\varepsilon_{\mathrm{c}, \mathrm{r}}}} \\
\alpha_{\mathrm{c}}=0.00022 f_{\mathrm{c}, \mathrm{r}}^{2.75}+0.746 \\
\alpha_{\mathrm{c}, \mathrm{f}} / \alpha_{\mathrm{c}}=1 /\left(1+2.43 \lambda_{\mathrm{f}}\right) \\
b_{\mathrm{f}} / b=1 /\left(1+0.386 \lambda_{\mathrm{f}}\right)
\end{gathered}
$$

where, $\sigma_{\mathrm{c}}$ and $\varepsilon_{\mathrm{c}}$ are the stress and the strain at any point of stress-strain curve, $n$ is a material parameter that depends on the shape of stress-strain curves, $f_{c, r}$ and $\varepsilon_{c, r}$ are the peak-stress and the peak-strain respectively, $E_{\mathrm{c}}$ is the modulus of elasticity of concrete. $\lambda_{\mathrm{f}}$ is the fiber factor.

The tested values of $\alpha_{\mathrm{cf}} / \alpha_{\mathrm{c}}$ and $b_{\mathrm{f}} / b$ for self-compacting SFRELC are displayed in Figures 15 and 16. A good fitness can be achieved compared with the calculation results of Formulas (6) and (7).

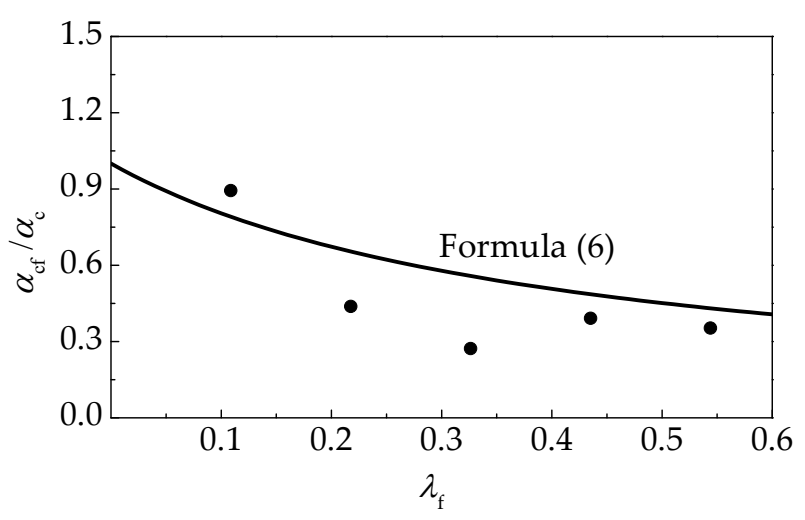

Figure 15. Relationship between $\lambda_{\mathrm{f}}$ and $\alpha_{\mathrm{cf}} / \alpha_{\mathrm{c}}$. 


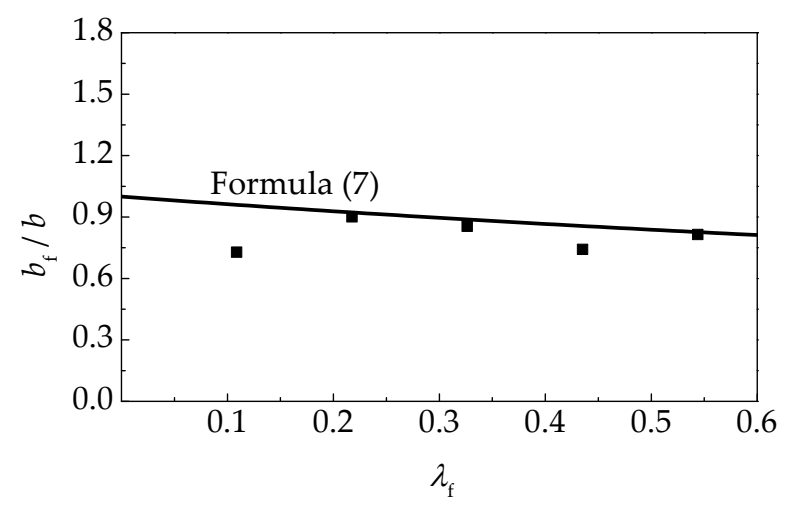

Figure 16. Relationship between $\lambda_{\mathrm{f}}$ and $b_{\mathrm{f}} / b$.

The relationship between $\varepsilon_{\mathrm{cu}} / \varepsilon_{\mathrm{c}, \mathrm{r}}$ and $\alpha_{\mathrm{c}}$ or $\alpha_{\mathrm{c}, \mathrm{f}}$ is shown in Figure 17, which fits the Formula (8) specified in China Code GB50010 for conventional concrete as follows [45],

$$
\frac{\varepsilon_{\mathrm{cu}}}{\varepsilon_{\mathrm{c}, \mathrm{r}}}=\frac{1}{2 \alpha_{\mathrm{cf}}}\left(1+2 \alpha_{\mathrm{cf}}+\sqrt{1+4 \alpha_{\mathrm{cf}}}\right)
$$

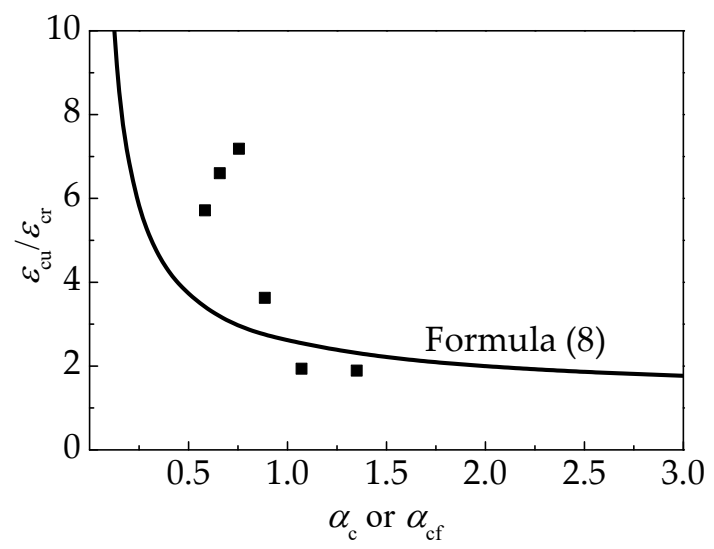

Figure 17. Relationship between $\varepsilon_{\mathrm{cu}} / \varepsilon_{\mathrm{c}, \mathrm{r}}$ and $\alpha_{\mathrm{c}} / \alpha_{\mathrm{c}, \mathrm{f}}$.

\subsection{Aslani' Model}

Aslani's model for compressive stress-strain curves is the same in form with Formula (2) [32-34]. The material parameter $n$ can be calculated by Formulas (9)-(14).

When $0 \leq \frac{\varepsilon_{\mathrm{c}}}{\varepsilon_{\mathrm{c}, \mathrm{r}}} \leq 1$,

$$
n=\left[1.02-1.17\left(E_{\mathrm{c} 1} / E_{\mathrm{c}}\right)\right]^{-0.74} .
$$

When $\frac{\varepsilon_{\mathrm{c}}}{\varepsilon_{\mathrm{c}, \mathrm{r}}}>1$,

$$
n=\left[1.02-1.17\left(E_{\mathrm{c} 1} / E_{\mathrm{c}}\right)\right]^{-0.74}+(\rho+28 \omega) .
$$

where,

$$
\begin{gathered}
\rho=\left(135.16-0.1744 f_{\mathrm{c}, \mathrm{r}}\right)^{-0.46} \\
\omega=0.83 \exp \left(-911 / f_{\mathrm{c}, \mathrm{r}}\right) \\
E_{\mathrm{c} 1}=\frac{E_{\mathrm{c}}(v-1)}{v} \\
v=\frac{f_{\mathrm{c}, \mathrm{r}}}{17}+0.8 .
\end{gathered}
$$


In these formulas, $E_{\mathrm{c} 1}$ is the secant modulus, and $\rho, \omega$ are the coefficients corresponding to the $f_{\mathrm{c}, \mathrm{r}}$ in Formula (10).

\subsection{Cunha' and FIP Model}

The basic form for Cunha's model and the FIP model [35-37] is presented as Formulas (15)-(17). When $\varepsilon_{\mathrm{c}} \leq \varepsilon_{\mathrm{c}, \mathrm{lim}}$

$$
\frac{\sigma_{\mathrm{c}}}{f_{\mathrm{c}}}=\frac{\frac{E_{\mathrm{c}}}{E_{\mathrm{c} 1}} \frac{\varepsilon_{\mathrm{c}}}{\varepsilon_{\mathrm{c}, \mathrm{r}}}-\left(\frac{\varepsilon_{\mathrm{c}}}{\varepsilon_{\mathrm{c}, \mathrm{r}}}\right)^{2}}{1+\left(\frac{E_{\mathrm{c}}}{E_{\mathrm{c} 1}}-2\right) \frac{\varepsilon_{\mathrm{c}}}{\varepsilon_{\mathrm{c}, \mathrm{r}}}}
$$

When $\varepsilon_{\mathrm{c}} \geq \varepsilon_{\mathrm{c}, \text { lim }}$

$$
\begin{gathered}
\frac{\sigma_{\mathrm{c}}}{f_{\mathrm{c}}}=\left\{\left[\frac{1}{\varepsilon_{\mathrm{c}, \mathrm{lim}} / \varepsilon_{\mathrm{c}, \mathrm{r}}} \xi\left(\frac{1}{2 \alpha}\right)^{2}-\frac{1}{\left(\varepsilon_{\mathrm{c}, \mathrm{lim}} / \varepsilon_{\mathrm{c}, \mathrm{r}}\right)^{2}} \frac{1}{\alpha}\right]\left(\frac{\varepsilon_{\mathrm{c}}}{\varepsilon_{\mathrm{c}, \mathrm{r}}}\right)^{2}+\left[\frac{1}{\varepsilon_{\mathrm{c}, \mathrm{lim}} / \varepsilon_{\mathrm{c}, \mathrm{r}}} \frac{2}{\alpha}-\xi\left(\frac{1}{2 \alpha}\right)^{2}\right] \frac{\varepsilon_{\mathrm{c}}}{\varepsilon_{\mathrm{c}, \mathrm{r}}}\right\}^{-1} \\
\xi=\frac{4\left[\left(\frac{\varepsilon_{\mathrm{c}, \mathrm{lim}}}{\varepsilon_{\mathrm{c}, \mathrm{r}}}\right)^{2}\left(\frac{E_{\mathrm{c}}}{E_{\mathrm{c} 1}}-2\right)+2 \frac{\varepsilon_{\mathrm{cllim}}}{\varepsilon_{\mathrm{c}, \mathrm{r}}}-\frac{E_{\mathrm{c}}}{E_{\mathrm{c} 1}}\right]}{\left[\frac{\varepsilon_{\mathrm{c}, \mathrm{lim}}}{\varepsilon_{\mathrm{c}, \mathrm{r}}}\left(\frac{E_{\mathrm{c}}}{E_{\mathrm{c} 1}}-2\right)+1\right]^{2}} .
\end{gathered}
$$

where, $\varepsilon_{\mathrm{c}, \text { lim }}$ is the limited strain at stress of $\alpha f_{\mathrm{c}, \mathrm{r}}$ which may be calculated by Formula (18).

$$
\varepsilon_{\mathrm{c}, \lim }=\frac{1}{2}\left[(1-\alpha) \frac{E_{\mathrm{c}}}{E_{\mathrm{c} 1}}+2 \alpha\right]+\left[\frac{1}{4}\left[(1-\alpha) \frac{E_{\mathrm{c}}}{E_{\mathrm{c} 1}}+2 \alpha\right]^{2}-\alpha\right]^{0.5}
$$

For Cunha's model, the parameter $\alpha$ is related to the curing age $t$ of concrete as presented in Formula (19), and value of $\alpha$ at curing age $t=28 \mathrm{~d}$ is 0.9 .

$$
\alpha=0.9 \exp \left\{0.005\left[1-\left(\frac{28}{t}\right)^{1.16}\right]\right\}
$$

For the FIP model, $\alpha=0.5$.

\subsection{Fitness with Tested Curves}

The tested compressive stress-strain curves are compared with the proposed model, Aslani's model, Cunha's model, and the FIP model, respectively. As exhibited in Figure 18, the good fitness by the four calculation models are in the order of the proposed model, Aslani's model, Cunha's model, and the FIP model. Based on the numerical analysis of test data, a similar conclusion will be obtained.

In this paper, the average predictive ratio of calculate to test stress $(A V G)$ and coefficient of variation $(C O V)$ at the same strain are used to evaluate the degree of fitting. Formulas (20)-(21) are used to calculate the $A V G$ and $C O V$ of fitting curves with the four models and results are displayed in Table 5 .

$$
\begin{gathered}
A V G=\left(\sum_{i=1}^{n} \frac{\sigma_{\mathrm{cal}}}{\sigma_{\mathrm{c}}}\right) / n \\
C O V=S D / A V G
\end{gathered}
$$

where, $\sigma_{\mathrm{c}}$ is the stress at any point of stress-strain curve,; $\sigma_{\mathrm{cal}}$ is the calculate stress at the same strain with $\sigma_{\mathrm{c}}$, and $S D$ is the standard deviation of $\sigma_{\mathrm{cal}} / \sigma_{\mathrm{c}}$. 


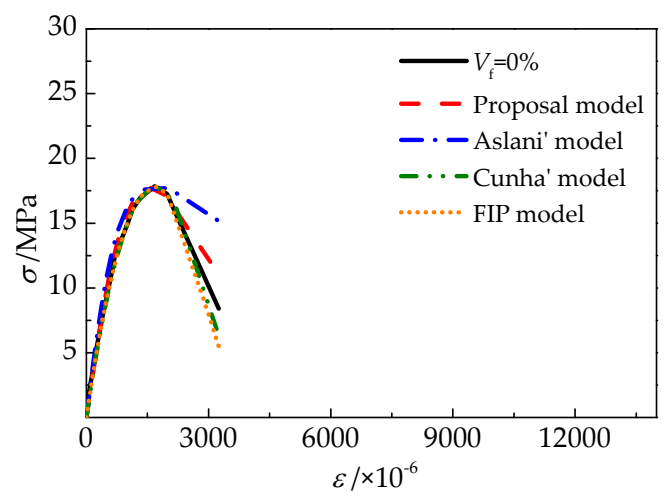

(a)

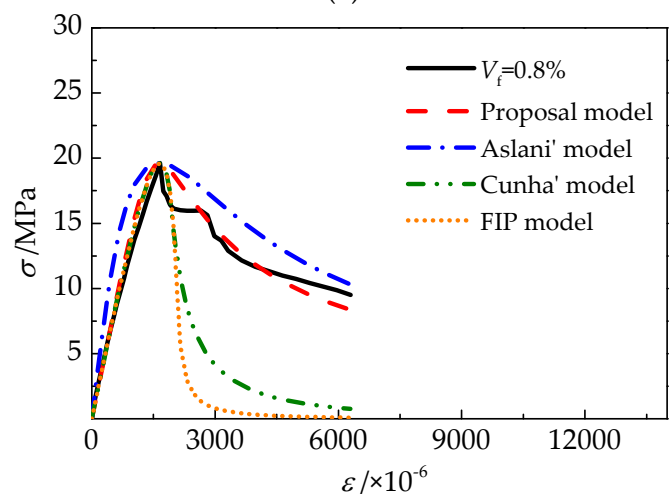

(c)

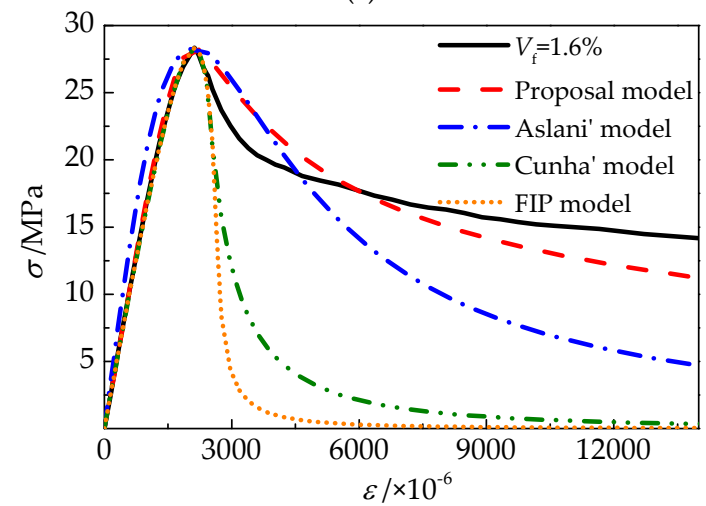

(e)

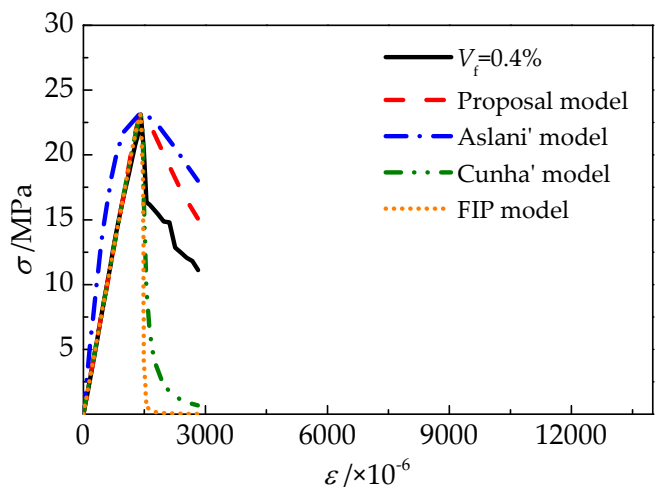

(b)

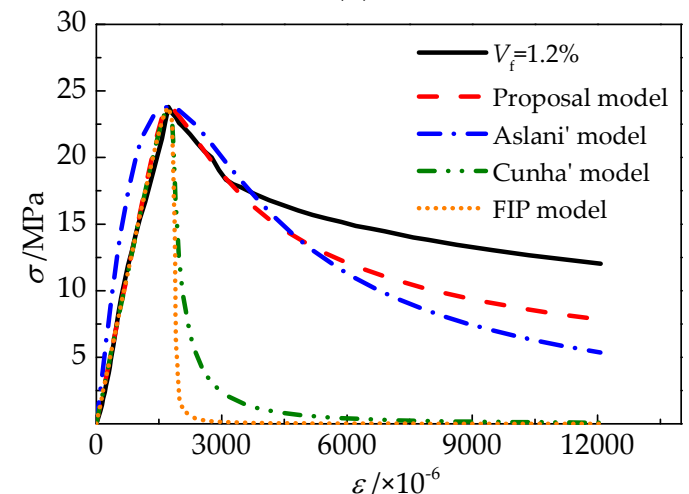

(d)

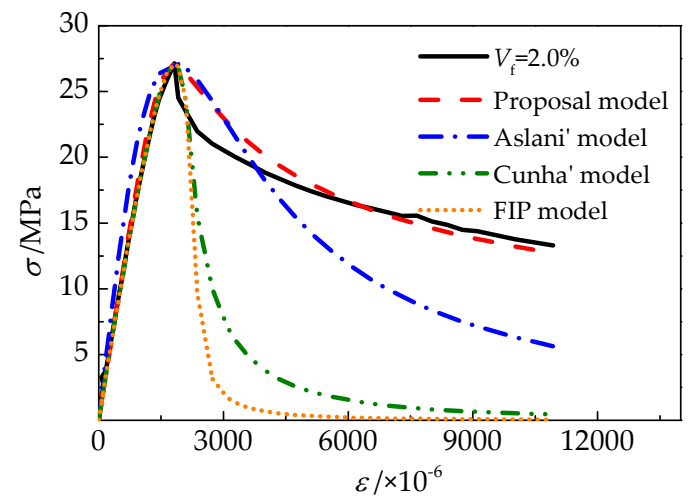

(f)

Figure 18. Test and calculated stress-strain curves of self-compacting SFRELC. (a) $v_{\mathrm{f}}=0 \%$; $(\mathbf{b}) v_{\mathrm{f}}=$ $0.4 \% ;(\mathbf{c}) v_{\mathrm{f}}=0.8 \% ;(\mathbf{d}) v_{\mathrm{f}}=1.2 \% ;(\mathbf{e}) v_{\mathrm{f}}=1.6 \% ;(\mathbf{f}) v_{\mathrm{f}}=2.0 \%$.

Table 5. Calculation results of $A V G$ and $C O V$.

\begin{tabular}{|c|c|c|c|c|c|c|c|c|c|c|c|c|c|c|c|c|}
\hline \multirow[b]{2}{*}{$v_{\mathrm{f}} / \%$} & \multicolumn{4}{|c|}{ Proposal Model } & \multicolumn{4}{|c|}{ Aslani's Model } & \multicolumn{4}{|c|}{ Cunha's Model } & \multicolumn{4}{|c|}{ FIP Model } \\
\hline & \multicolumn{2}{|c|}{$\begin{array}{l}\text { Ascending } \\
\text { Portion }\end{array}$} & \multicolumn{2}{|c|}{$\begin{array}{l}\text { Ascending } \\
\text { Portion }\end{array}$} & \multicolumn{2}{|c|}{$\begin{array}{l}\text { Ascending } \\
\text { Portion }\end{array}$} & \multicolumn{2}{|c|}{$\begin{array}{l}\text { Descending } \\
\text { Portion }\end{array}$} & \multicolumn{2}{|c|}{$\begin{array}{l}\text { Ascending } \\
\text { Portion }\end{array}$} & \multicolumn{2}{|c|}{$\begin{array}{l}\text { Descending } \\
\text { Portion }\end{array}$} & \multicolumn{2}{|c|}{$\begin{array}{l}\text { Ascending } \\
\text { Portion }\end{array}$} & \multicolumn{2}{|c|}{$\begin{array}{c}\text { Descending } \\
\text { Portion }\end{array}$} \\
\hline 0 & 1.017 & 0.177 & 1.08 & 0.144 & 0.875 & 0.198 & 1.234 & 0.309 & 0.875 & 0.181 & 0.947 & 0.138 & 0.458 & 0.345 & 0.807 & 0.281 \\
\hline 0.4 & 1.018 & 0.023 & 1.303 & 0.101 & 1.603 & 0.2 & 1.413 & 0.143 & 1.019 & 0.023 & 0.359 & 0.981 & 1.019 & 0.023 & 0.153 & 2.152 \\
\hline 0.8 & 0.988 & 0.134 & 1.025 & 0.088 & 1.38 & 0.125 & 1.158 & 0.051 & 0.969 & 0.122 & 0.456 & 0.837 & 0.969 & 0.122 & 0.3 & 1.396 \\
\hline 2.0 & 0.935 & 0.185 & 1.036 & 0.065 & 1.153 & 0.168 & 0.825 & 0.315 & 0.911 & 0.177 & 0.304 & 1.099 & 0.911 & 0.177 & 0.182 & 1.685 \\
\hline
\end{tabular}

For the proposed model, $A V G$ and $C O V$ in the ascending portion are 0.935-1.101 and 0.019-0.185, while those in the descending portion are $0.991-1.303$ and $0.065-0.156$, with the volume fraction of steel fiber varying from $0 \%$ to $2.0 \%$. For Aslani's model, $A V G$ and $C O V$ in the ascending portion are 
$0.875-1.665$ and $0.090-0.273$, and those in the descending portion are $0.811-1.413$ and $0.051-0.356$. For Cunha's model, AVG and COV in the ascending portion are $0.875-1.098$ and $0.023-0.181$, and those in the descending portion are 0.189-0.947 and 0.138-1.557. For the FIP model, AVG and COV in the ascending portion are $0.458-1.098$ and $0.023-0.345$, and those in the descending portion are $0.092-0.300$ and 0.281-2.765. These results display that nearly all of the four models but Aslani's model have a good prediction for the ascending portion of the test curves. The proposed model is an effective predictor for complete test curves of self-compacting SFRELC. Aslani's model shows a good fitness for curves of $v_{\mathrm{f}}=0-0.8 \%$, but slightly worse than the proposed model when $v_{\mathrm{f}}=1.2-2.0 \%$. Both Cunha's model and the FIP model are inappropriate for the prediction of the descending portion in compressive stress-strain curves of self-compacting SFRELC.

\section{Conclusions}

Based on the test results and analysis, the following conclusions can be drawn:

(1) Self-compacting SFRELC with a slump flow of larger than $600 \mathrm{~mm}$ was prepared in this experiment. Slump-flow and J-ring slump-flow decreased while slump-flow time $\left(T_{500}\right)$ increased with the increase of $v_{\mathrm{f}}$. Drying densities increased about $12.2 \%$ with the $v_{\mathrm{f}}$ increased from $0 \%$ to $2.0 \%$.

(2) With the increasing $v_{\mathrm{f}}$, the uniaxial compressive stress-strain curves of self-compacting SFRELC trends to be steep at ascending portion and a slower slope at descending portion. With the $v_{\mathrm{f}}$ varying from $0 \%$ to $2.0 \%$, the increments of $f_{\mathrm{cu}}, f_{\mathrm{c}, \mathrm{r}}$ and $\varepsilon_{\mathrm{c}, \mathrm{r}}$ are $35.5 \%, 51.3 \%$ and $27.1 \%$ respectively. Values of $f_{\mathrm{c}, \mathrm{r}}$ are about $0.6-0.8$ times $f_{\mathrm{cu}}$, which may be attributed to the loading rate being slower than that used in the test of axial compressive strength. The residual strengths increased with the increase of volume fraction of steel fiber.

(3) With the $v_{\mathrm{f}}$ varied from $0.4 \%$ to $1.2 \%$, the toughening effect of steel fiber was outstanding, and the increments of $W_{\mathrm{c}, 1.0}$ and $R_{\mathrm{e}, 1.0}$ are $59 \%$ and $54.5 \%$, respectively. When the $v_{\mathrm{f}}$ reached to $1.6 \%$ and $2.0 \%$, the $W_{\mathrm{c}, 1.0}$ and $R_{\mathrm{e}, 1.0}$ had no significant promotion. Therefore, the optimal $v_{\mathrm{f}}$ for self-compacting SFRELC can be taken as $1.2 \%$.

(4) Based on the values of $A V G$ and $C O V$ for the predictive ratios, and a comparison of calculations and test curves, the proposed model has a good fitness with the tested curves of self-compacting SFRELC, and Aslani's model is slightly worse. Cunha's model and the FIP model are suitable for the ascending portion, but inappropriate for the descending portion. As such, the proposed model is suggested in this paper.

Author Contributions: Methodology, M.Z. and S.Z.; Tests, Data Interpretation and Writing-Original Draft Preparation, M.Z., B.Z., P.S. and Y.F.; Writing-Review and Editing, M.Z. and X.Z.; Writing-Review and Funding Acquisition, X.Z. and S.Z.

Funding: This study was funded by [State Key Research and Development Plan, China] grant number [2017YFC0703904], [NCWU Innovation Funds for Doctoral Candidate] grant number [201715601], [Key Scientific and Technological Research Project of University in Henan, China] grant number [16A560024], and [Innovative Sci-Tech Team of Eco-building Material and Structural Engineering of Henan Province, China] grant number [YKRZ-6-066].

Conflicts of Interest: The authors declare no conflict of interest.

\section{References}

1. JGJ 51-2002. Ministry of Housing and Urban-Rural Construction of the People's Republic of China. Technical Specification of Lightweight Aggregate Concrete; China Building Industry Press: China, Beijing, 2002. (In Chinese)

2. JGJ12-2006. Ministry of Housing and Urban-Rural Construction of the People's Republic of China. Technical Specification for Lightweight Aggregate Concrete Structures; China Building Industry Press: China, Beijing, 2006. (In Chinese)

3. Hassanpour, M.; Shafigh, P.; Mahmud, H.B. Lightweight aggregate concrete fiber reinforcement-A review. Constr. Build. Mater. 2012, 37, 452-461. [CrossRef] 
4. Zhao, S.B.; Li, C.Y.; Qian, X.J. Experimental study on mechanical properties of steel fiber reinforced full lightweight concrete. Geotech. Special Pub. 2011, 212, 233-239.

5. Pan, L.Y.; Yuan, H.; Zhao, S.B. Experimental study on mechanical properties of hybrid fiber reinforced full lightweight aggregate concrete. Adv. Mater. Res. 2011, 197-198, 911-914. [CrossRef]

6. Li, C.Y.; Chen, H.; Zhao, S.B. Mechanical properties of steel fiber reinforced light-aggregate concrete. Adv. Mater. Res. 2012, 366, 12-15. [CrossRef]

7. Li, X.K.; Shen, Z.; Chen, M.H.; Zhao, M.S. Experimental study on compressive properties of steel-fiber-reinforced lightweight-aggregate fly-ash concrete. J. Guangxi Univ. Nat. Sci. Ed. 2015, 1, 106-111. (In Chinese)

8. Shen, Z.; Chen, M.H.; Zhao, M.S.; Li, X.K. Experimental study on tensile properties of steel fiber reinforced lightweight-aggregate fly-ash flowable concrete. In Architectural Engineering and New Materials; DEStech Publications, Inc.: Lancaster, PA, USA, 2015; pp. 1-8.

9. Zhao, M.L.; Zhao, M.S.; Chen, M.H.; Li, J.; Law, D. An experimental study on strength and toughness of steel fiber reinforced expanded-shale lightweight concrete. Constr. Build. Mater. 2018, 183, 493-501. [CrossRef]

10. Li, X.K.; Zhang, X.Y.; Li, M.Q.; Zhao, M.S.; Li, C.Y. Experiments on development of strength and carbonization of steel fiber reinforced full-lightweight concrete. J. Civ. Eng. Manage. 2017, 2, 46-50. (In Chinese)

11. Zhao, S.B.; Zhao, M.S.; Zhang, X.Y.; Peng, Z.J.; Huang, T.H. Study on complete stress-strain curves of steel fiber reinforced lightweight-aggregate concrete under uniaxial compression. J. Build. Struct. 2019, 5, 181-190. (In Chinese)

12. Li, X.K.; Li, C.Y.; Zhao, M.L.; Yang, H.; Zhou, S.Y. Testing and prediction of shear performance for steel fiber reinforced expanded-shale lightweight concrete beams without web reinforcements. Materials 2019, $12,1594$. [CrossRef] [PubMed]

13. Zhao, M.S.; Zhang, X.Y.; Song, W.H.; Li, C.Y.; Zhao, S.B. Development of steel fiber reinforced expanded-shale lightweight concrete with high freeze-thaw resistance. Adv. Mater. Sci. Eng. 2018, 2018, 9573849.

14. Zhao, S.B.; Li, C.Y.; Zhao, M.S.; Zhang, X.Y. Experimental study on autogenous and drying shrinkage of steel fiber reinforced lightweight-aggregate concrete. Adv. Mater. Sci. Eng. 2016, 2016, 2589383. [CrossRef]

15. Li, J.J.; Chen, Y.H.; Wan, C.J. A mix-design method for lightweight aggregate self-compacting concrete based on packing and mortar film thickness theories. Constr. Build. Mater. 2017, 157, 621-634. [CrossRef]

16. Wu, Z.M.; Zhang, Y.G.; Zheng, J.J.; Ding, Y.N. An experimental study on the workability of self-compacting lightweight concrete. Constr. Build. Mater. 2009, 23, 2087-2092. [CrossRef]

17. Wang, Y.M.; Liu, X.J. Mix proportion design and basic mechanical property experiment of self- compacting lightweight concrete. Concrete 2012, 6, 111-113. (In Chinese)

18. Wu, X.; Wang, J.F.; Fan, X.L.; Zhang, X.; Wu, Z.M. Thermal behavior of self-compacting lightweight concrete subjected to the elevated temperature. J. Mater. Sci. Eng. 2014, 32, 313-317. (In Chinese)

19. Iqbal, S.; Ali, A.; Holschemacher, K.; Bier, T.A. Mechanical properties of steel fiber reinforced high strength lightweight self-compacting concrete (SHLSCC). Constr. Build. Mater. 2015, 98, 325-333. [CrossRef]

20. Zhang, Y.G.; Wu, X.; Bi, Q.W. Shrinkage and creep performance of self-consolidating lightweight concrete. J. Mater. Sci. Eng. 2014, 32, 35-39. (In Chinese)

21. $\mathrm{Wu}, \mathrm{X}$; Fu, T.F.; Wu, Z.M. Experimental study on double- $K$ fracture parameters and fracture energy of self-consolidating lightweight concrete. Eng. Mech. 2010, 27, 249-254. (In Chinese)

22. Wang, Z.Y.; Ding, J.T.; Guo, Y.S. Stress-strain curves of structural lightweight aggregate concretes. Concrete. 2005, 3, 39-41. (In Chinese)

23. Liu, X.; Yin, J.; He, Y.Q.; Hou, Y. Experimental study of stress-strain curves of lightweight aggregate concrete. J. Inner Mongolia Univ. Sci. Technol. 2010, 29, 277-280. (In Chinese) [CrossRef]

24. Wang, Y.Q.; Wang, C.R.; Chen, Y.X.; Ni, Y. Stress-strain relationships for concrete in axial compression. J. Tianjin Univ. 1983, 2, 29-40. (In Chinese)

25. Campione, G.; Mendola, L.L. Behavior in compression of lightweight fiber reinforced concrete confined with transverse steel reinforcement. Cem. Concr. Compos. 2004, 26, 645-656. [CrossRef]

26. Floyd, O.S.; Arthur, H.N.; Salvador, M. Mechanical properties of high-strength lightweight concrete. ACI J. 1986, 83, 606-613.

27. Zhang, M.H.; Gjvorv, O.E. Mechanical Properties of High-Strength Lightweight Concrete. Aci Mater. J. 1991, $88,240-247$. 
28. Shannag, M.J. Characteristics of lightweight concrete containing mineral admixtures. Constr. Build. Mater. 2011, 25, 658-662. [CrossRef]

29. Oğuz, A.D.; Rüstem, G.; Abdulkadir, C.A. Effect of steel fibers on the mechanical properties of natural lightweight aggregate concrete. Mater. Lett. 2005, 59, 3357-3363.

30. Shafigh, P.; Mahmud, H.; Jumaat, M.Z. Effect of steel fiber on the mechanical properties of oil palm shell lightweight concrete. Mater. Des. 2011, 32, 3926-3932. [CrossRef]

31. Lucyna, D. Modification of properties of structural lightweight concrete with steel fibres. J. Civ. Eng. Manag. 2011, 17, 36-44.

32. Ding, X.X.; Li, C.Y.; Li, Y.Z.; Lu, Y.Z.; Song, C.; Zhao, S.B. Experimental and numerical study on stress-strain behavior of self-compacting SFRC under uniaxial compression. Constr. Build. Mater. 2018, 185, 30-38. [CrossRef]

33. Aslani, F.; Nejadi, S. Mechanical characteristics of self-compacting concrete with and without fibres. Mag. Concr. Res. 2013, 65, 608-622. [CrossRef]

34. Aslani, F.; Nejadi, S. Self-compacting concrete incorporating steel and polypropylene fibers: Compressive and tensile strengths, moduli of elasticity and rupture, compressive stress-strain curve, and energy dissipated under compression. Compos. Part B Eng. 2013, 53, 121-133. [CrossRef]

35. Cunha, V.M.C.F.; Barros, J.A.O.; Sena-Cruz, J. Modelling the influence of age of steel fibre reinforced self-compacting concrete on its compressive behavior. Mater. Struct. 2008, 41, 465-478. [CrossRef]

36. Aslani, F.; Natoori, M. Stress-strain relationships for steel fiber reinforced self-compacting concrete. Struct. Eng. Mech. 2013, 46, 295-322. [CrossRef]

37. Comité Euro-International du Béton. CEB-FIP Model Code 1990-Design Code; Redwood Books: Trowbridge, UK, 1993.

38. GB 175-2007. General Administration of Quality Supervision, Inspection and Quarantine of the People's Republic of China. Common Portland Cement; China Standard Press: Beijing, China, 2007. (In Chinese)

39. GB/T 1596-2005. General Administration of Quality Supervision, Inspection and Quarantine of the People's Republic of China. Fly Ash Used for Cement and Concrete; China Standard Press: Beijing, China, 2005. (In Chinese)

40. GB/T 17431.2-2010. Ministry of Housing and Urban-Rural Construction of the People's Republic of China. Lightweight aggregates and Its Test Methods_Part 2: Test Methods for Lightweight Aggregates; China Building Industry Press: Beijing, China, 2010. (In Chinese)

41. JGJ/T 283-2012. Ministry of Housing and Urban-Rural Construction of the People's Republic of China. Technical Specification for Application of Self-compacting Concrete; China Building Industry Press: Beijing, China, 2012. (In Chinese)

42. GB/T 50081-2002. Ministry of Housing and Urban-Rural Construction of the People's Republic of China. Standard for Test Method of Mechanical Properties on Ordinary Concrete; China Building Industry Press: Beijing, China, 2002. (In Chinese)

43. CECS 13:2009. Ministry of Housing and Urban-Rural Construction of the People's Republic of China. Standard Test Methods for Fiber Reinforced Concrete; China Standard Press: Beijing, China, 2009. (In Chinese)

44. American Concrete Institute. Design Considerations for Steel Fiber Reinforced Concrete; ACI 544.4R; ACI Committee 544: Farmington Hills, MI, USA, 1988.

45. GB 50010-2010. Ministry of Housing and Urban-Rural Construction of the People's Republic of China. Code for Design of Concrete Structures; China Building Industry Press: Beijing, China, 2010. (In Chinese)

(C) 2019 by the authors. Licensee MDPI, Basel, Switzerland. This article is an open access article distributed under the terms and conditions of the Creative Commons Attribution (CC BY) license (http://creativecommons.org/licenses/by/4.0/). 